\title{
Twin sisters with Hashimoto's thyroiditis and Henoch-Schönlein purpura
}

\author{
Yu-Xue Wang1, Min Liu'², Ying Cheng², Xiao-Juan He², Ya-Li Zhang1, Xin-Liang Wang1, \\ ${ }^{1}$ Department of Pediatrics, The Second Hospital of Hebei Medical University, Shijia Zhuang, China \\ ${ }^{2}$ Department of Pediatrics, The Second Hospital of HanDan, HanDan, China
}

Key words: Hashimoto thyroiditis (HT); Henoch-Schönlein purpura (HSP); twin

\section{Patient 1}

The child was eight years old and was a twin younger sister. She was admitted to the hospital due to ecchymosis on the skin of both lower limbs for more than 10 days and joint pain for two days. When examined on admission she had a body temperature of $36.5^{\circ} \mathrm{C}$, a respiratory rate of 25 breaths per min, and a heart rate of 100 beats per min. She was conscious, the skin of both lower extremities had large bloody spots that were higher than the skin, the eyes were slightly convex, the lymph nodes were not swollen, the heart sound was strong, the heart rate was 100 beats per min, the heart rhythm was regular, and the abdomen was soft with no tenderness. There was no redness or swelling of the joints of the limbs. Blood tests revealed that the platelets (PLT) had no obvious abnormalities. Due to characteristics of skin blemishes in a child, case 1 was analysed, the diagnosis was HSP. After admission, anti-infective, anti-allergic, haemostasis, and other treatments were given. After treatment, the child's rash gradually subsided, her condition improved, and she was discharged.

\section{Patient 2}

The child was eight years old and was a twin older sister. She was admitted to the hospital due to skin congestion. On physical examination, scattered ecchymosis was found on both legs and buttocks. The ecchymosis did not fade after pressing. Both eyeballs were prominent, the thyroid normal by palpation, and no obvious abnormalities were found in the heart, lungs, and abdomen. On admission she was diagnosed with HSP. Anti-infective, anti-allergic, and other treatments were given after admission. The child's rash gradually subsided.

During hospitalisation, due to the obvious bulging of both the eyeballs, the patient's history was revealed and analysed. The child's eyes had obviously been protruding from a young age, and at the same time, the twin sister also had prominent eyes without obvious symptoms of polyphagia, hyperhidrosis, palpitation, and chills. In order to determine the cause of the obvious bulking of the double eyeballs, eight thyroid examinations were performed. The levels of free triiodothyronine (fT3) and free thyroxine (fT4) were normal, the levels of total T3 (TT3) decreased, and the thyroglobulin antibody (TGAb) was significantly increased. Considering thyroid dysfunction in children, it was considered that HT may be present.

A thyroid colour ultrasound showed that the older sister had thyroid enlargement, with a left lobe of $38 \times 13 \times 12 \mathrm{~mm}$, a right lobe of $38 \times 14 \times 12 \mathrm{~mm}$, and an isthmus thickness of $6.5 \mathrm{~mm}$, and that the echo was uneven and the blood supply was rich. The thyroid function test results on 2012.10.31 were: TSH - $0.16 \mu \mathrm{IU} / \mathrm{mL}$ (0.27-4.2), FT3 - $7.34 \mathrm{pmol} / \mathrm{L}$ (3.10-6.8), FT4 - 29.45 pmol/L (12-22), T3 - $1.2 \mathrm{nmol} / \mathrm{L}$ (1.3-3.1), $\mathrm{T} 4-112.5 \mathrm{nmol} / \mathrm{L}(66-181), \mathrm{A}-\mathrm{TG}->600 \mathrm{IU} / \mathrm{mL}(\leq 34)$, $\mathrm{rT3}-0.22 \mathrm{ng} / \mathrm{mL}(0.2-0.6)$, and TPOAb $->600.0$ $\mathrm{IU} / \mathrm{mL}(0-34)$. The younger sister's thyroid was also enlarged, with a left lobe of $38 \times 16 \times 15 \mathrm{~mm}$, a right lobe of $38 \times 16 \times 15 \mathrm{~mm}$, and an isthmus thickness of $5.4 \mathrm{~mm}$, and the echo was uneven and the blood supply was abundant. The thyroid function test results on 2012.10.31 were: TSH $-88.09 \mu \mathrm{IU} / \mathrm{mL}(0.27-4.2)$, FT3 - $5.57 \mathrm{pmol} / \mathrm{L}(3.10-6.8), \mathrm{FT} 4-8.19 \mathrm{pmol} / \mathrm{L}(12-22)$, $\mathrm{T} 3-2.1 \mathrm{nmol} / \mathrm{L}(1.3-3.1), \mathrm{T} 4-58.4 \mathrm{nmol} / \mathrm{L}(66-181)$, 


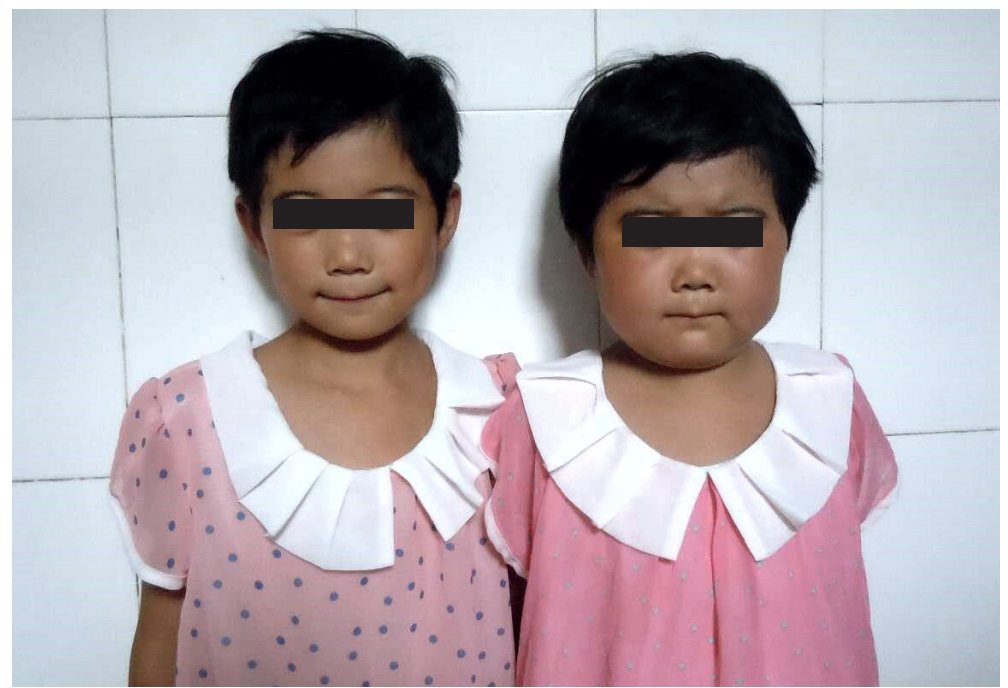

Figure 1. Patients are twin sisters, on the left is elder sister, on the right is younger sister

A-TG $->600 \mathrm{IU} / \mathrm{mL}(\leq 34), \mathrm{rT3}-0.42 \mathrm{ng} / \mathrm{mL}(0.2-0.6)$, and TPOAb $>600.0 \mathrm{IU} / \mathrm{mL}(0-34)$. According to the above examinations and signs, HT was diagnosed. Methimazole and other treatments were given, and regular reviews were conducted to control the disease (Fig. 1).

After eight months, the older sister was re-admitted to hospital with abdominal pain. She was discharged from hospital after treatment with methylprednisolone. Genetic testing was performed, and the results were normal; thyroid function was also normal.

Hashimoto's thyroiditis is insidious and chronic, and clinical manifestations are diverse and atypical, so it is easy to miss diagnosis and to misdiagnose it. The disease is a T-cell-mediated organ-specific autoimmune thyroid disease, and its exact pathogenesis is still unclear [1]. Henoch-Schönlein purpura (HSP) is a systemic vasculitis affecting the small vessels. It is clinically characterised by palpable purpura and is often associated with arthralgia, diffuse abdominal pain, renal involvements, haematuria, and proteinuria. The aetiology and pathogenesis of HSP have not been fully elucidated [2,3].

If not treated in time, as the disease progresses, thyroid function will gradually decrease, affecting the normal growth and development of children [4]. The twins discussed in this report have goitres and theirs antibodies was significantly elevated (TPO > 600
$\mathrm{IU} / \mathrm{mL}$ ), which was strongly positive and met the diagnostic criteria of HT [5]. Since birth, the twins' eyes protruded, but this was not taken seriously by their family. The pathogenesis of HT and HSP has not been fully elucidated; however, both are related to the abnormal immune function of the body. Tlymphocyte dysfunction, humoral immune disorder, and abnormal cytokine secretion, inflammatory mechanism, and genetic susceptibility are involved in the pathogenesis of both diseases. Twins with HT are rare, and twins both suffering from HSP is even rarer. This paper has many shortcomings. It is necessary to explore whether these two diseases are associated with genetics in these cases. More genetic testing support could provide additional research clues about the pathogenesis of HT and HSP.

\section{References}

1. Yamada H, Itoh M, Hiratsuka I, et al. Circulating microRNAs in autoimmune thyroid diseases. Clin Endocrinol (Oxf). 2014; 81(2): 276-281, doi: 10.1111/cen.12432, indexed in Pubmed: 24533739.

2. Saulsbury FT, Saulsbury FT. Clinical update: Henoch-Schönlein purpura. Lancet. 2007; 369(9566): 976-978, doi: 10.1016/S0140-6736(07)60474-7, indexed in Pubmed: 17382810.

3. Morawiec-Szymonik E, Foltyn W, Marek B, et al. Pernicious anaemia and endocrine glands antibodies. Endokrynol Pol. 2019; 70(2): 143-150, doi: 10.5603/EP.a2018.0086, indexed in Pubmed: 30648728.

4. Leung AKC, Leung AAC. Evaluation and management of the child with hypothyroidism. World J Pediatr. 2019; 15(2): 124-134, doi: 10.1007/s12519-019-00230-w, indexed in Pubmed: 30734891.

5. Soh SB, Aw TC. Laboratory Testing in Thyroid Conditions - Pitfalls and Clinical Utility. Ann Lab Med. 2019; 39(1): 3-14, doi: 10.3343/alm.2019.39.1.3, indexed in Pubmed: 30215224. 